\title{
Producer-buyer interaction under mass customization: analysis through automotive industry
}

\author{
Arshia Khan ${ }^{1} \cdot$ Hans-Dietrich Haasis ${ }^{2}$
}

Received: 30 April 2016/ Accepted: 6 August 2016/Published online: 22 August 2016

(c) The Author(s) 2016. This article is published with open access at Springerlink.com

\begin{abstract}
Automotive companies have successfully adopted mass customization. However, this production method has complicated the sales process as the customer has to go through a lot of steps to specify the product. Thus, it is important that the sales process is modified to make the producer-buyer interaction efficient in mass customization. There is no study that examines whether the modifications in the sales processes of the automotive industry are according to the needs of mass customization. In this context, we investigate this relation for two leading automotive companies, for the customers of the USA, from 2008 till 2015. By applying statistical calculations, we observe that the increase in mass customization has actually declined customer satisfaction of the sales process. Hence, there is a further need to modify the sales process according to the needs of mass customization. Otherwise, the long-term success of mass customization of a car manufacturer is at risk.
\end{abstract}

Keywords Producer-buyer linkage $\cdot$ Sales process $\cdot$ Mass customization $\cdot$ Automotive industry

This article is part of a focus collection on "Dynamics in Logistics: Digital Technologies and Related Management Methods".

Arshia Khan

arshia@uni-bremen.de

Hans-Dietrich Haasis

Haasis@uni-bremen.de

1 International Graduate School, University of Bremen, 0.11 Wing-Building Wilhelm-Herbst-Str. 12, 28359 Bremen, Germany

2 Faculty 7: Business Studies and Economics, University of Bremen, Postbox 3304 40, 28334 Bremen, Germany

\section{Introduction}

Mass customization has replaced or supplemented mass production in many parts of the world [1]. The main focus of this production system is to meet the individual customer demand with minimal loss of efficiency [2]. Thus, it demands very sophisticated linkages. Since customer and buyer rely on each other to create the desired product, mass customization demands two-way communications (from buyer to producer and from producer to buyer) instead of one-way communication (only from producer to buyer) [3]. The communication between producer and buyer is mainly achieved through the sales process. Under mass customization, the latter is involved in a lot of processes, i.e., picking choices, opting service, filling forms. If the sales process fails to transfer customer's idea to the producer or it further confuses the person, then the success of mass customization is at stake. Hence, the efficiency of the sales process is of vital importance in the mass customization.

In modern times, the automotive industry has propelled rapidly toward mass customization. If we consider producerbuyer linkage within the automotive industry, we recognize that customer to producer interaction is more complicated here. Automotive is usually bought through a dealer, and customers rarely want to order their car online. So the dealer has to explain the options, the possible combinations and the different packages available to the customers. Thus, the sales process becomes much more complicated for the dealer as they are the main messengers between the producer and the buyer. It is very important that they are trained properly to guide customers during the buying process. Another aspect of the sales process in the automotive industry is that customizing a car also takes time as many steps, e.g., painting, assembling and delivering processes are according to customer choices. Hence, it requires time which may lead to the 
decrease in the satisfaction of the customer. All these factors demonstrate that adoption of mass customization is much more complex in the automotive industry than in other small products industries [4]. However, despite all these challenges, many automotive companies adopted mass customization quite successfully.

Since mass customization complicates the sales process for automotive companies, it is important to investigate whether the automotive companies have modified the sales process according to the needs of mass customization or not. As here exists no such study, we investigate the association between mass customization and sales process efficiency for two leading automotive companies (which are quite successful in the adoption of mass customization) and evaluate that whether they are also successful in the modification of the sales process. To address the problem in more detail, we analyze the existing literature in Sect. 2. In Sect. 3, we investigate the problem through a statistical investigation of two automotive companies. In Sect. 4, we discuss the results of the statistical calculations. Last, we conclude our work and give an outlook on future studies in Sect. 5.

\section{Literature analysis}

Although mass customization provides customer with large number of varieties, this does not automatically generate an added value for the customer [5]. It is observed that high level of options offered to customer may confuse him instead of increasing his satisfaction. It may also lead to the production of the product which is not desired by the customer [6]. Moreover, it is investigated that the relationship between numbers of choices offered and perceived satisfaction can be bidirectional. Customers can be overwhelmed by the high number of choices while in some cases it is found that customer may find large assortments as frustrating [7]. Selection process can be complicated long, and customer might experience an uncertainty. Sales management is one of the tools to get customer out of this frustration and uncertainty, and it should be designed to simplify the relation between customer and producer [8]. In other words, we can say that mass customization requires customized marketing strategies. It needs sophisticated changes in the sales process which should be focused to comfort customer during configuration process, and mass customization is thought to be a step toward realization of mass customization [9]. There are many literatures which emphasize on the different production strategies under mass customization. However, research on how customers will co-design with producer is very rare [8]. Companies claim to produce thousands of different products under mass customization, but the question arises that do these companies translate their ability to produce thousands of products into shopping and purchasing attitude of customer. Thus, in the current study, the main focus is to investigate customer satisfaction perceived from the sales processes, while the adoption of mass customization. To make our analysis more specific, we are addressing this issue for the automotive industry.

By considering mass customization under automotive industry, we figured out that relation between producer and buyer becomes more complex here. The main reason is that in the automotive industry, this relation is distorted by the third party "dealer". Since the relation is not direct, it needs sophistication. Moreover, since it takes time and complexities to produce a car, so in-time delivery also becomes a problem. Thus, various such factors, e.g., dealers, dealership facility, selling management, delivery time, complicate the sales procedure [4]. It is also investigated that different e-services (which include different online services of ordering, complaining, configuring, etc.) could be used to facilitate customer in mass customization process. [10]. However, in the case of automotive customers, it is observed that customer relies more on dealer as compared to these e-services [11]. So customer value achievement under mass customization in automotive industry is of greater concern [4].

Importance of customer satisfaction from sales process for the automotive industry has been emphasized in the literature also [12]. There is a study about Portugal that reveals different factors behind customer satisfaction for automotive industry. It investigates the relation between producer and customer via qualitative analysis, for three automotive companies: Toyota, Ford and Renault. It emphasizes that selling behavior, supportiveness provided, after sales services and perceived quality have a significant role toward customer satisfaction [12]. Sales strategies should be given importance to make the customer more satisfied. It should not be ignored that the producer to buyer interaction is one of the major concerns of the supply chain; this part has an important role in the achievement of getting higher customer value and has got a significant place in the modern supply chain [13]. Moreover, it should also be noted that mass customization has given different results to different companies. Volkswagen claims to save $\$ 1.7$ billion annually [14], while Opel lost \$747 million in 2011 [15]. This is due to different operational strategies [4]. So, sales modifications for automotive industry under mass customization are a matter of concern.

The above-mentioned arguments lead to a question that whether in the automotive industry has the sales process been modified according to the needs of mass customization. If we look into the literature, we cannot find any study which specifically deals with this issue. The purpose of this paper is to fill this literature gap. Our focus will be to consider the implications of mass customization on 
producer-buyer relationship in downstream supply chain. Hence, we will investigate whether modifications adopted by car companies are sufficient to meet the challenges of mass customization or not.

\section{Methodology}

To address the research problem, we are taking two cases from the automotive companies. The selected companies have adopted mass customization successfully, and this will help us to figure out that whether the companies also focused on the modification of downstream supply chain. Our focus will be on the quantitative analysis. First, we fix measures for the satisfaction of customer regarding the buying process and for the mass customization itself. Based on these data, we perform a statistical analysis.

\subsection{Data analysis}

In the current study, we have chosen to analyze the data for US automotive customers of BMW and Mercedes-Benz from 2008 till 2015.

\subsubsection{Measuring the extent of mass customization}

Mass customization can be measured by investigating the number of available options. Automotive companies are providing different options to customers for tailoring their products. However, for a customer, the selection of advanced options like driver assistance package and different sports packages is much more difficult than color selections. So, most automotive companies provide yes/no options for advanced packages, while for the upholstery, trim and exterior colors different choices have to be opted. The measure of the extent of customization is called cus- options for wheel, $x 5=$ no of individual options available, $x 6=$ no of additional packages, $x 7=$ no. of steering wheel options.

For both of the selected companies, customers are allowed to customize the car through phenomena known as "Build your own car". We evaluated CE for different models of each company, i.e., for Mercedes-Benz the evaluated models are $\mathrm{C}$ class, E class, $\mathrm{G}$ class, Cls class and $\mathrm{S}$ class, while for BMW series 7, 6, 3 and 1 are used. It is found that for each company in each year, customization options are almost same for all models. However, to get more valid results, we evaluated CE for every model separately and took the averages to get the final values, shown in Table 1 in "Appendix".

\subsubsection{Satisfaction perceived by the customer}

To measure customer satisfaction regarding the sales process, we follow the approach introduced in the J.D. Power studies [16]. There, the authors constructed a number of indicators, which describe different aspects of automotive companies.

One of the significant indexes developed by the study is sales satisfaction index (SSI), which gives a comprehensive analysis of the new-vehicle purchase experience from the customer perspective response with respect to purchase, delivery, sales and price. We employ the SSI index to measure for satisfaction given two different categories: buyers (who ultimately buy the product) and rejecters (who due to some of the reason leave the product). In accordance with the J.D. Power studies, we utilized a weight of $51 \%$ for buyers and $49 \%$ for rejecters [16] to compute SSI for US automotive customers via the formula shown in Eq. 2. Since SSI is constructed by using a large amount of data, it allows to generate a meaningful picture of customer satisfaction regarding the sales process. tomization extent (CE). It is comprised of the number of options available for trim, paint, packages, upholstery, wheels, etc.

$$
\mathrm{CE}=\prod_{i=1}^{7} x i
$$

where $x 1=$ no. of options for paint, $x 2=$ no. of options for upholstery, $x 3=$ no. of options for trim, $x 4=$ no of
The weights for subcategories proposed in [16] are given in Table 2, shown in "Appendix". We like to note that all variables shown in Table 2 are impacted by mass customization. Since mass customization adds a lot of complexity to the buying process, it demands modern dealership facilities, informed sales persons and efficient dealing. Similarly, delivery time is important in the case of mass customization because cars are mainly assembled after the placement of the customer's order. 


\subsection{Measuring relation between $\mathrm{CE}$ and SSI}

Data organized for CE and SSI are shown in Table 3, in "Appendix". After getting quantitative data on both indicators for the mentioned companies, we can use statistical techniques to analyze the relation between the two. To measure the link between the two variables, we utilized the Spearman rank correlation [17]. This test is without any limitations; thus, it can give us meaningful details regarding the interdependency of the variables.

\subsubsection{Spearman ranks correlation test}

Spearman rank correlation is used to investigate the strength of the link between two data sets. It is an alternative to linear regression and correlation. There are several advantages of using Spearman rank. Most importantly, it helps to get rid of outliers. The null and alternative hypothesis for the test are as follows:

$\mathbf{H}_{\mathbf{0}}$ There is no relation between two variables

$\mathbf{H}_{\mathbf{1}}$ There is relation between two variables

The Spearman rank correlation can be calculated with the help of the following formula:

$r=1-\frac{6 \sum d_{i}^{2}}{n\left(n^{2}-1\right)}$

where we use $d_{i}=\mathrm{CE}_{i}-\mathrm{SSI}_{i}$, for respective years $i$ and $n$ represents the number of observations for SSI or CE.

The value of the coefficient " $r$ " ranges from -1 to +1 . If the value turns out to be zero, we will accept the null hypothesis, otherwise we reject it. The $\mathrm{r}$ value of -1 suggests that the relation is strongly negative, while +1 suggests that two variables are correlated strongly positive [18].

\subsubsection{Validation of the test results}

In statistics, it is important to validate the result obtained from any test. Here, we apply a significance test to determine whether the results obtained from the Spearman rank correlation regarding the association between mass customization and sales process efficiency are valid or not. Most commonly the $T$ test is used for this purpose [19]. We apply the $T$ test with the following null and alternative hypothesis:

$\mathbf{H}_{\mathbf{0}}$ There is no correlation between mass customization and sales efficiency in the population

$\mathbf{H}_{\mathbf{1}}$ There is correlation between mass customization and sales efficiency in the population
With the above-mentioned hypothesis, the next task is to evaluate the $T$ test via the formula:

$t=r / \sqrt{\left(1-r^{2}\right) /(n-2)}$

where $r$ is the Spearman coefficient, calculated from Eq. 3, and $\mathrm{n}$ represents the number of observations for SSI or CE.

The results of the $t$ tests are checked with the help of rule of thumb for this test, which states that "If the $T$ value is greater than $|2|$, it shows that relation between the two variables is statistically significant, so we can reject the null hypothesis and vice versa" [20]. Rule of thumb is estimated for a $95 \%$ confidence interval.

\section{Results}

Utilizing the data and methods from Sect. 3, we obtain the following results.

Results from Spearman rank correlation test Source: Authors calculation

\begin{tabular}{|c|c|c|c|c|}
\hline Test & Company & $R$ & $T$ value & Interpretation \\
\hline \multirow[t]{2}{*}{$\begin{array}{l}\text { Spearman rank } \\
\text { correlation } \\
\text { test }\end{array}$} & BMW & -0.64 & -2.04 & $\begin{array}{l}\text { Strong and } \\
\text { significant } \\
\text { negative relation }\end{array}$ \\
\hline & $\begin{array}{l}\text { Mercedes- } \\
\text { Benz }\end{array}$ & -0.29 & -0.28 & $\begin{array}{l}\text { Week and } \\
\text { insignificant } \\
\text { negative relation }\end{array}$ \\
\hline
\end{tabular}

As shown in the table, the results from the test are similar for both companies regarding respective signs but are different in impact and significance. Overall, the results are negative for both companies. This shows that the correlation between mass customization and satisfaction regarding the sales process is negative. We cannot say that the rise in one variable causes decline in other, as correlation does not mean causality. However, we can say that with the overall rise in mass customization producer-buyer linkage is weakened. This implies that the sales process is not modified according to the needs of the new production system in both automotive companies.

The results of the two companies are different in strength and significance. In the case of BMW, we observe that company has a vast program for carrying out mass customization. The company has developed various options in design and combination. However, we see that with the increase in the mass customization, the satisfaction from the sales process has declined significantly. There is a strong negative and significant relation between mass customization and sales process efficiency, which shows that the sales process was not modified accordingly. The results from Mercedes-Benz are not different from BMW. 
Yet, unlike BMW there is weak and insignificant negative relation between the mass customization and sales process efficiency. This implies that Mercedes-Benz should also improve the sales process efficiency. However, it must be noted that the customization program of Mercedes-Benz has not declined the customer satisfaction from sales process as much as in the case of BMW.

Hence, the above-mentioned results imply that the modification of the sales process is not sufficiently elaborated. It should be noted that in calculating SSI, delivery time has also been taken into account. With the advance in customization, it becomes difficult to customize the product in time, which causes unrest in the customers. Furthermore, with the increase in delivery time, customer preference and choices may change leading to decrease in his level of satisfaction. Another important reason behind these results can be involvement of the third party. As the above-mentioned studies are for USA, it must be noted that most people prefer to buy through a dealer instead of buying online [18]. The dealer has the responsibility to read the customers mind and transfer it to a producer. Thus, if the dealer fails, it results in customer dissatisfaction regarding the sales process or even in the dissatisfaction regarding the mass customization.

Moreover, we like to note that these results do not mean that mass customization is unsuccessful in the mentioned companies; it might be possible that two companies are very efficient in the adoption of mass customization from different prospects; however, the companies have not sufficiently modified the sales process.

\section{Conclusion and future outlook}

Mass customization attracts customers but at the same time, it complicates the downstream supply chain. The main reason for this is that in mass customization the producer has to read the customer mind, a phenomenon which influences the producer-buyer relation. There is enough literature which shows how production should be modified to meet the needs of mass customization. However, the importance of modifications in the sales procedure is ignored. The question is raised in this study that whether in the automotive industry the modifications carried out in the sales procedure are enough to meet the requirements of mass customization.

To investigate this question, we considered the cases of two automotive companies, BMW and Mercedes-Benz. We evaluated the quantitative data for the customers of the USA for both companies from 2008 to 2015. Firstly, we developed an indicator to measure the extent of customization (CE). Secondly, to measure the sales process efficiency, we used the SSI developed by J.D. Power studies. After organizing data, we used statistical tests to compute the correlation between customization extent and efficiency in the sales process via the Spearman rank correlation test. Moreover, we applied the $T$ test to check the significance. The results obtained were negative for both companies which imply that with the increase in mass customization the efficiency in the sales process has declined, or in other words, producer-buyer linkage has weakened. However, the results of Mercedes-Benz are better than of BMW. The former has weak and insignificant association between SSI and CE, while the latter has strong negative and significant relation. Yet, both companies need to consider further modifications in the sales process.

Literature focuses a lot on modifications in the production procedure, while there is hardly any study which brings out the importance of sales management under mass customization or suggests how sales procedures should be modified to meet mass customization challenges. To fill this gap, this paper brings out that sales procedures modifications under mass customization should be given significant importance. The empirical analysis showed that automotive companies are not modifying the sales procedures enough to meet customization challenges. Producer to buyer interaction should be made as simple as possible. There is need to bring out more sophisticated changes in sales procedures under mass customization. Many sales criteria like simple selection process, delays in delivery, price fairness and dealer's availability are the areas to focus on, apart from the different mass customization production techniques. Moreover, further work can be done to validate the results of this study through expert interview, analyzing the above-mentioned variables for forecasting purposes or using other statistical techniques.

Acknowledgments This research is supported by the GSSP program of the IGS funded by the DAAD.

Open Access This article is distributed under the terms of the Creative Commons Attribution 4.0 International License (http://crea tivecommons.org/licenses/by/4.0/), which permits unrestricted use, distribution, and reproduction in any medium, provided you give appropriate credit to the original author(s) and the source, provide a link to the Creative Commons license, and indicate if changes were made.

\section{Appendix}

See Tables 1, 2 and 3. 
Table 1 Customization calculation for BMW 6er and Mercedes-Benz CLS for US customers Source: Authors calculation using broachers of the companies

\begin{tabular}{|c|c|c|c|c|c|c|c|c|c|c|c|c|}
\hline \multirow{2}{*}{$\begin{array}{l}\text { BMW series } 6 \\
2015\end{array}$} & \multicolumn{2}{|c|}{ Exterior colors } & \multicolumn{2}{|c|}{ Upholstery } & \multirow{2}{*}{$\begin{array}{l}\text { Trim } \\
6\end{array}$} & \multicolumn{2}{|c|}{ Wheel } & \multicolumn{2}{|c|}{ Steering wheel } & Packages & Additional options & \multirow{2}{*}{$\frac{\mathrm{CE}}{891,072}$} \\
\hline & 17 & & 12 & & & 4 & & 2 & & 7 & 13 & \\
\hline 2014 & 17 & & 11 & & 6 & 4 & & - & & 7 & 13 & 408,408 \\
\hline 2013 & 16 & & 16 & & 6 & 4 & & - & & 7 & 13 & 559,104 \\
\hline 2012 & 16 & & 16 & & 6 & 4 & & - & & 7 & 13 & 559,104 \\
\hline 2011 & 16 & & 16 & & 6 & 4 & & - & & 7 & 13 & 559,104 \\
\hline 2010 & 13 & & 5 & & 3 & 3 & & - & & 3 & 13 & 22,815 \\
\hline 2009 & 13 & & 6 & & 3 & 3 & & - & & 3 & 15 & 31,590 \\
\hline 2008 & 11 & & 6 & & 3 & 3 & & - & & 3 & 15 & 26,730 \\
\hline \multicolumn{2}{|c|}{ Mercedes-Benz CLS 550} & \multicolumn{2}{|c|}{ Exterior colors } & \multicolumn{2}{|c|}{ Upholstery } & Trim & & & Steering wheel & Packages & Additional options & $\mathrm{CE}$ \\
\hline 2015 & & 15 & & 11 & & 5 & 4 & & - & 5 & 5 & 82,500 \\
\hline 2014 & & 9 & & 3 & & 4 & 2 & & - & 5 & 6 & 6480 \\
\hline 2013 & & 10 & & 3 & & 2 & 2 & & - & 5 & 6 & 3600 \\
\hline 2012 & & 9 & & 3 & & 2 & 3 & & - & 5 & 8 & 6480 \\
\hline 2011 & & 10 & & 3 & & - & - & & - & 2 & 2 & 120 \\
\hline 2010 & & 10 & & 3 & & - & - & & - & 3 & 2 & 180 \\
\hline 2009 & & 13 & & 3 & & - & - & & - & 3 & 2 & 234 \\
\hline 2008 & & 11 & & 4 & & 2 & 2 & & - & 6 & 6 & 6336 \\
\hline
\end{tabular}

There are several models used to calculate CE; here we present how to it is calculated only for one model of each company

Table 2 Variables weigh in SSI Source: Table constructed from the information in J.D. Power Associates [16]

\begin{tabular}{lll}
\hline Variable & Rejecter/buyer & Weight $(\%)$ \\
\hline Working out deal & Buyer & 17 \\
Sales person & Buyer & 13 \\
Delivery process & Buyer & 11 \\
Dealership facility & Buyer & 10 \\
Sales person & Rejecter & 20 \\
Fairness of price & Rejecter & 12 \\
Facility & Rejecter & 6 \\
Inventory & Rejecter & 6 \\
Experience negotiation & Rejecter & 5 \\
\hline
\end{tabular}

Table 3 Data for customization extent and sales satisfaction index Source: CE calculated by author using several models of the respective companies, and SSI data are from J.D. Power Associates

\begin{tabular}{lllllr}
\hline \multirow{2}{*}{ Year } & \multicolumn{2}{l}{ BMW } & & \multicolumn{2}{c}{ Mercedes-Benz } \\
\cline { 2 - 3 } & SSI & CE & & SSI & \multicolumn{1}{c}{ CE } \\
\hline 2015 & 731 & $1,695,157$ & & 749 & 427,707 \\
2014 & 727 & $1,663,214$ & & 761 & 89,784 \\
2013 & 712 & $2,098,880$ & & 728 & 55,900 \\
2012 & 714 & 665,348 & & 717 & 15,789 \\
2011 & 677 & 486,248 & & 701 & 7298 \\
2010 & 799 & 106,821 & & 815 & 13,806 \\
2009 & 861 & 23,490 & & 877 & 9655 \\
2008 & 884 & 35,568 & & 897 & 5917 \\
\hline
\end{tabular}

\section{References}

1. Cox WM, Alm R (1998) The right stuff: America's move to mass customization. Econ Rev Fed Reserve Bank Dallas 3-26

2. Liu G, Deitz GD (2011) Linking supply chain management with mass customization capability. Int J Phys Distrib Logist Manag 41(7):668-683

3. Mittal V, Katrichis JM, Kumar P (2001) Attribute performance and customer satisfaction over time: evidence from two field studies. J Serv Mark 15(5):343-356

4. Pollard D, Chuo S, Lee B (2011) Strategies for mass customization. J Bus Econ Res 6(7):77-86

5. Quelch JA, Kenny D (1994) Extend profits, not product lines. Harvard Bus Rev 72(5):153-160

6. Huffman C, Kahn BE (1998) Variety for sale: mass customization or mass confusion? J Retail 74(4):491-513

7. Kahn BE (1998) Dynamic relationships with customers: highvariety strategies. J Acad Mark Sci 26(1):45-53

8. Piller Frank (2003) Managing high variety: how to overcome the mass confusion phenomenon of customer co-design. University of Applied Sciences Basel, Diss

9. Wind J, Rangaswamy A (2001) Customerization: the next revolution in mass customization. J Int Mark 15(1):13-32

10. Grenci RT, Watts CA (2007) Maximizing customer value via mass customized e-consumer services. Bus Horiz 50(2):123-132

11. Wells John D, Gobeli David H (2003) The 3R framework: improving e-strategy across reach, richness, and range. Bus Horiz 46(2):5-14

12. Loureiro SM, Sardinha IMD, Reijnders L (2012) The effect of corporate social responsibility on consumer satisfaction and perceived value: the case of the automobile industry sector in Portugal. J Clean Prod 37:172-178

13. Patterson PG, Johnson LW, Spreng RA (1996) Modeling the determinants of customer satisfaction for business-to-business professional services. J Acad Mark Sci 25(1):4-17 
14. Gershenson JK, Prasad GJ, Zhang Y (2003) Product modularity: definitions and benefits. J Eng Des 14(3):295-313

15. http://gmauthority.com/blog/2012/12/gm-should-have-dumpedopel-when-it-had-the-chance-opinion-desk/. Seen on 21 Feb 2016

16. J.D. Power Associates press release (2011). http://businesscenter. jdpower.com/news/pressrelease.aspx?ID=2011199. Seen on 21 Feb 2016

17. McDonald JH (2009) Handbook of biological statistics, vol 2. Sparky House Publishing, Baltimore, pp 173-181
18. Zar JH (1972) Significance testing of the Spearman rank correlation coefficient. J Am Stat Assoc 67(339):578-580

19. Solihull N (2001) Mass customization: a long march. The Economist: Keeping the Customer Satisfied 67-19

20. Mason RD, Lind DA, Marchal WG (1999) Statistical techniques in business and economics, 10th edn. McGraw-Hill, Boston 